\title{
Assessment of indoor air quality in university classrooms
}

\author{
Michal Kraus ${ }^{1, *}$, and Petra Nováková ${ }^{1}$ \\ ${ }^{1}$ Institute of Technology and Business in České Budějovice, Department of Civil Engineering, \\ 370 01, České Budějovice, Czech Republic
}

\begin{abstract}
This contribution describes the subjective assessment process of indoor environmental conditions in university classrooms. The university campus consisting of several buildings is situated on the outskirts of the town of Čské Budějovice (South Bohemia, Czech Republic). A high level of indoor environment quality (IEQ) is a key factor to achieve healthy environments in buildings. Suitable indoor air quality is more important in schools and universities (no-industrial civic amenities) than in many other buildings. Indoor air quality in the university environment affects learning processes, concentration, and productivity of students. It also could affect the health of students and teachers in longterm. Students are at greater risk because of the hours spent in educational facilities. The evaluation of the subjective assessment of the quality of the indoor environment at university classrooms is described within the paper.
\end{abstract}

\section{Introduction}

Insufficient quality of the indoor environment for the learning purpose can prevent students and teachers from progressing in their learning process. Students' attention may stray away from learning goals due to the influence of the internal environment and its determining parameters. The indoor environment is defined by a number of partial elements - thermal and humidity parameters, ventilation, lighting, acoustics, odours, and microbial, aerosol and ionization factor [1]. The parameters of indoor air quality (IAQ) influence not only health but also the ability to learn and work. The results of the studies show that in the case of full occupancy of the classrooms, the indoor air quality deteriorates rapidly. The concentration of Carbon dioxide $\left(\mathrm{CO}_{2}\right)$ in the classrooms is rapidly rising [2]. Other independent studies demonstrate the effect of internal quality on performance and productivity [3-6]. The quality of the internal environment in schools also influences the student-perceived social climate [7].

\section{Methodology}

Four university classes (A-D) are selected in the city of České Budějovice, South Bohemia, Czechia in order to investigate the university indoor environment. One of the tested

\footnotetext{
*Corresponding author: info@krausmichal.cz
} 
university classes is the computer classroom (C). The walls and ceilings are fitted with a classic internal plaster with white paint. Flooring is PVC linoleum. The windows are new, plastic with a shading system of internal blinds. The classroom equipment is classical and includes tables, chairs, whiteboard, computer and projector. The survey was conducted during April. The climate in České Budějovice during April is cool and reasonably dry. Daytime maximum temperatures average around a cool $13^{\circ} \mathrm{C}$, whilst at night $3^{\circ} \mathrm{C}$ is normal.

Environmental quality assessment is based on subjective perception. Before the assessment, the panels (students) were instructed how to use the scale. There is no restriction on the distribution of gender or smoking habits. The age ranged from 20 to 23 years. All panellists are bachelor students. The panellists stay outdoor odors before the assessments. Before the lesson, the panellists indicated their immediate evaluation on six continuous scales regarding air acceptability, odor intensity, thermal comfort, humidity comfort, light comfort and noise load. Then the percentage of dissatisfied (PN) was estimated. The scale of air acceptability is divided into 2 separates scales with end-point clearly acceptable $(+1)$ / just acceptable (0) and just unacceptable (0) /clearly unacceptable $(-1)$. The scale of odor intensity has five levels of intensity odor: 0 no odor, 1 slight odor, 2 moderate odor, 3 strong odor, 4 very strong odor and 5 overwhelming odor. According to ASHRAE the scale of thermal comfort has 7 levels: +3 hot, +2 warm, +1 slightly warm, 0 neutral, -1 slightly cool, -2 cool, -3 cold. The humidity scale has 5 levels: $2+$ too humid, +1 slightly humid, 0 just right, -1 slightly dry and -2 too dry. The range of perceived lighting levels has 5 level: +2 too bright, +1 slightly bright, 0 just right, -1 slightly dark and -2 too dark. The noise load scale is divided into 5 levels: 1 no noise, 2 slight noise, 3 acceptable noise, 4 strong noise and 5 intolerable noise. After the lesson, the students left the classroom and the classroom was closed. Students stayed outside over a few minutes due to limitation of acclimatization. Then the students returned to the classroom and re-evaluated the quality of the indoor environment after the lesson.

\section{Results}

The results of the subjective assessment of the quality of the indoor environment are shown in Figures 1-6. Summary results including trends are shown in Table 1.

Figure 1 shows the box plots of air acceptability for all testes classrooms before and after the lesson. With the exception of the computer classroom (C), students rated the air acceptability after teaching less than at the beginning.

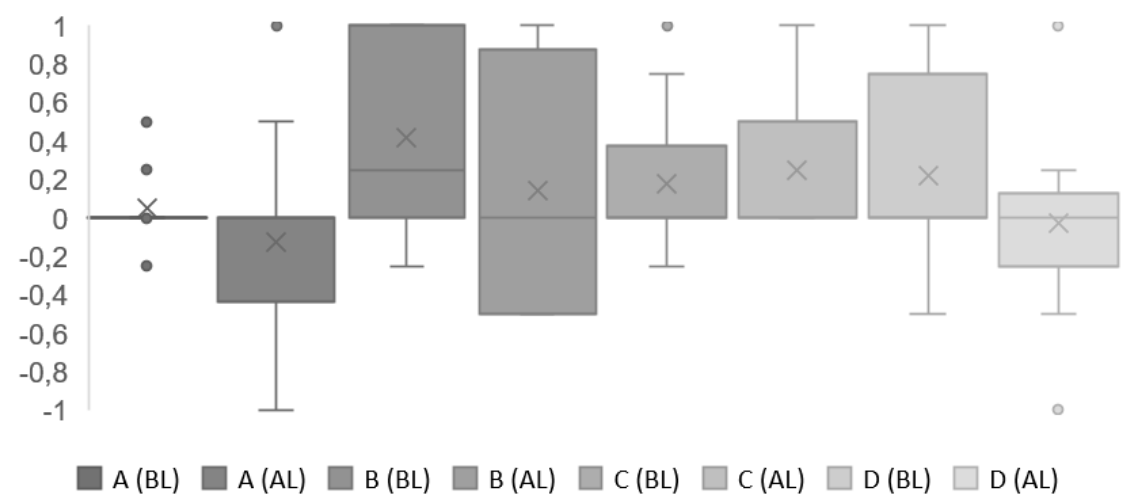

Fig. 1. Air acceptability in the university classrooms before (BL) and after (AL) the lesson. 


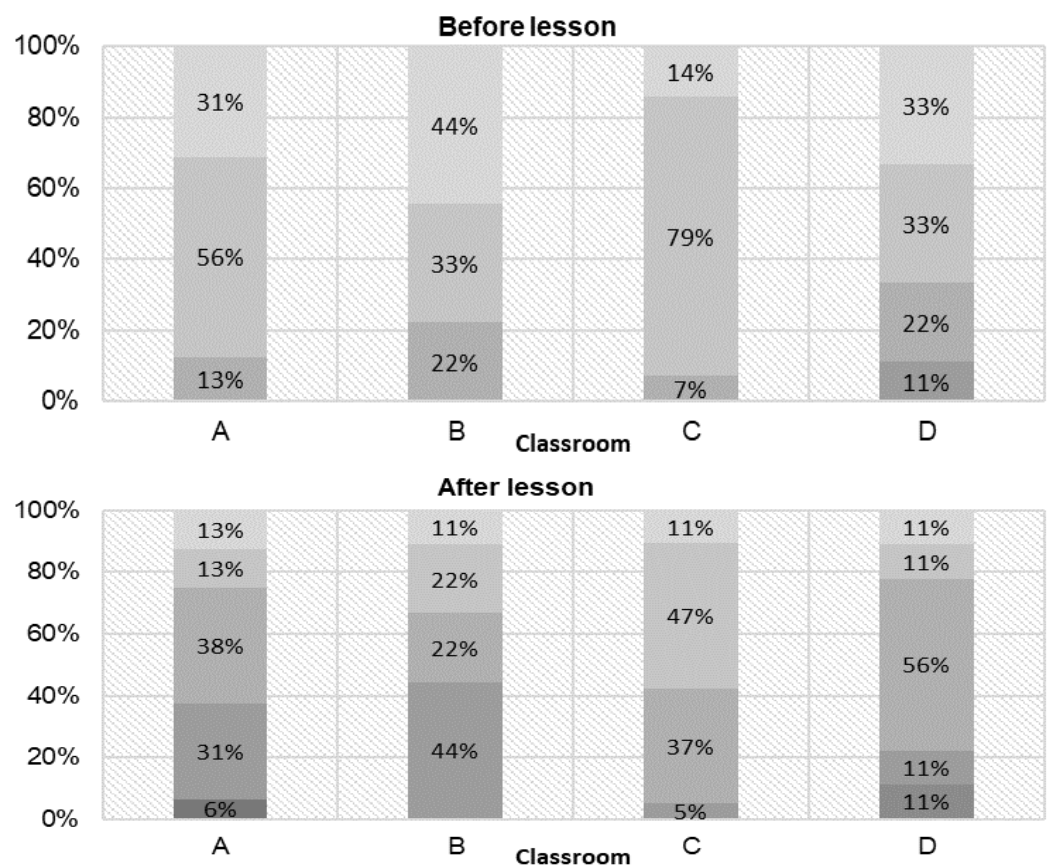

m Overwhelming odor $\mathbf{m}$ Very strong odor $\mathbf{m}$ Strong odor $\mathbf{m}$ Moderate odor $\mathbf{m}$ Slight odor $\mathbf{m}$ No odor

Fig. 2. Odor intensity in the university classrooms before and after the lesson.

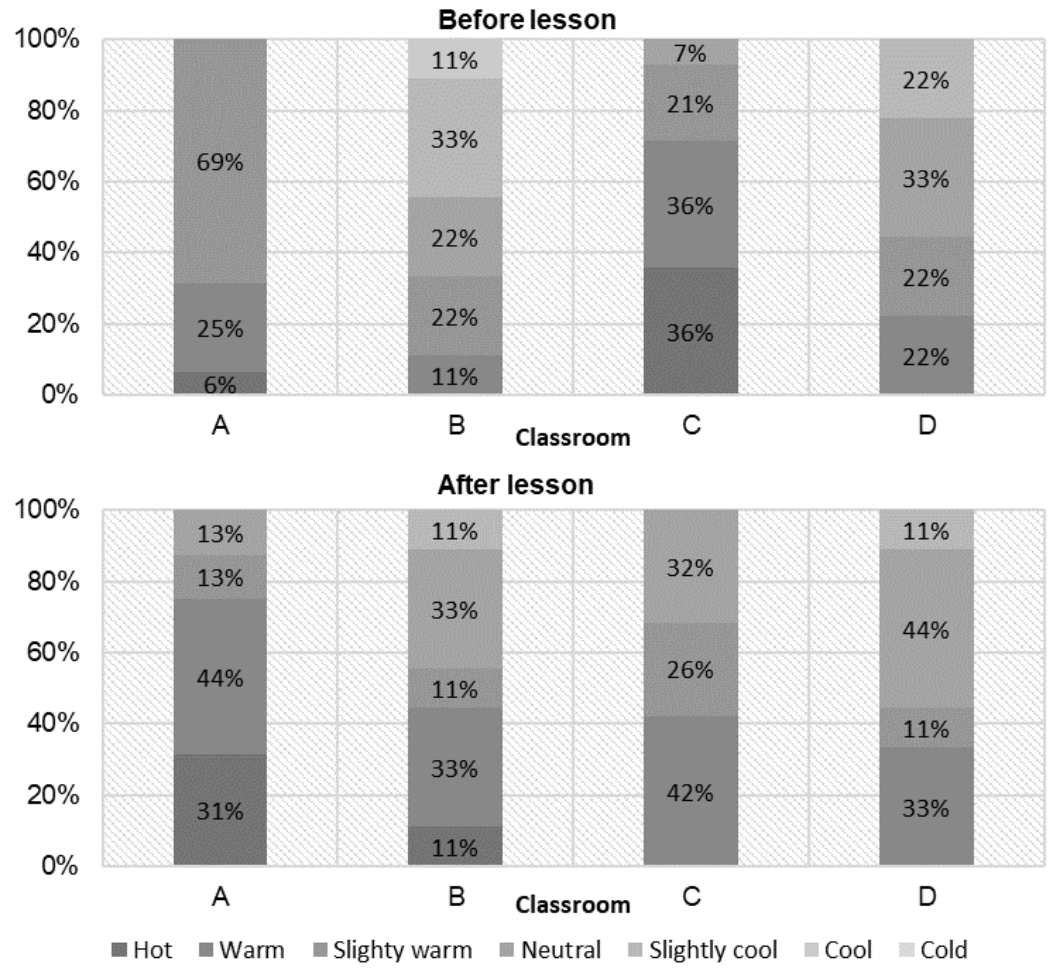

Fig. 3. Thermal comfort in the university classrooms before and after the lesson. 
The mean value of odor intensity for all university classes is 2.00 before the lesson and 2.21 after the lesson. It means slightly odor which can have represented rising concentration of Carbon dioxide. The deterioration trend of the indoor environment is monitored only for the computer classroom (C). Other classrooms maintain a stable odor level. The $6 \%$ of panellists evaluate classroom A as unsatisfactory after teaching.

Results of thermal comfort illustrated in Figure 3 corresponds with the trend of odor intensity. The mean value is between slightly warm and warm. It has to be noted that the research took place during the heating season. About $2 \%$ of panellists evaluate the indoor environment as too warm (unacceptable) before the class starts. The percentage of dissatisfied students is already more than $11 \%$.

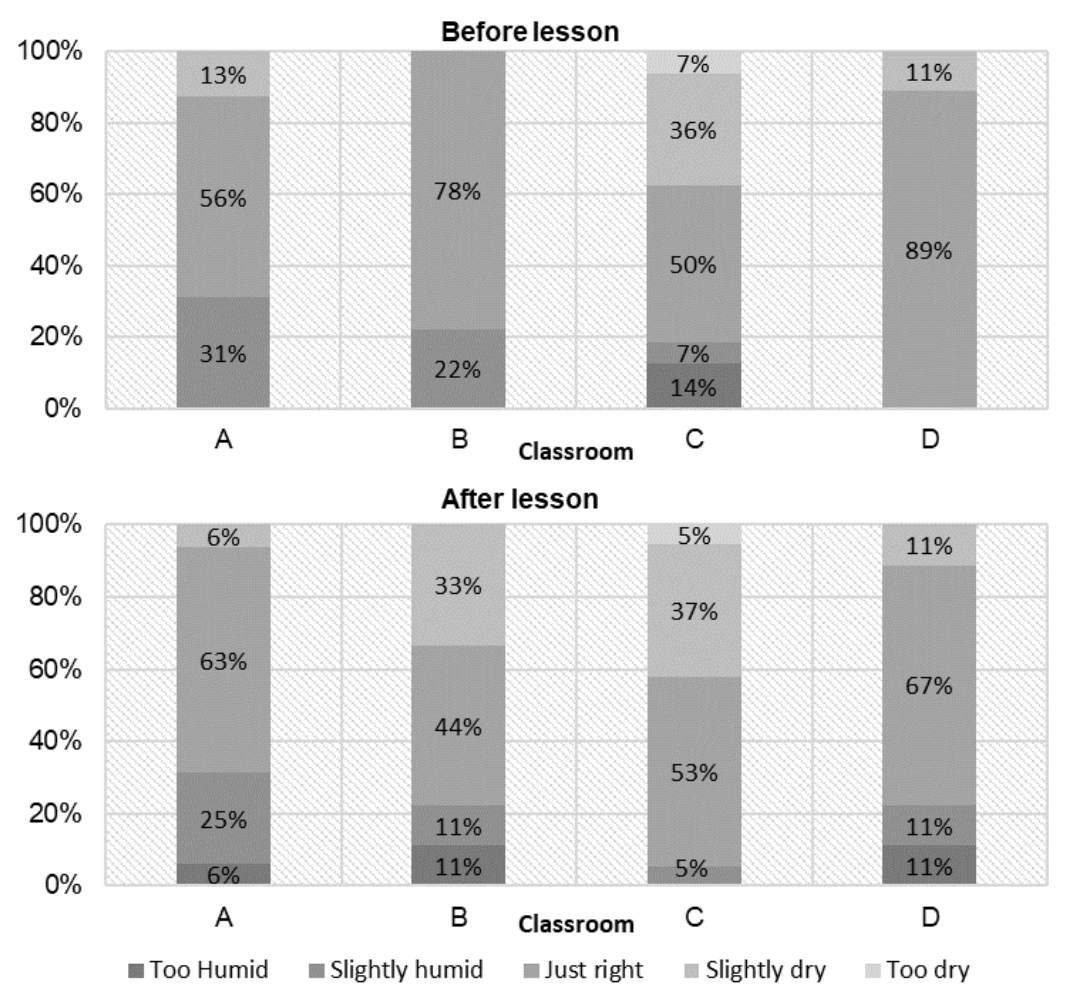

Fig. 4. Humidity comfort in the university classrooms before and after the lesson.

Figure 4 shows the results of humidity comfort. The feeling of humidity or dryness depends on the amount of water contained in air and air temperature. Hygrothermal microclimate is an essential part of indoor air quality. The mean value of perceived humidity comfort oscillated between slightly humid and too humid levels. Percentage of unacceptable (too humid or too dry) is $6 \%$ before the lesson and $7.5 \%$ after the lesson.

The mean value of light comfort is 2.40 before the lesson and 2.65 after the lesson. The mean value is acceptable and represents the slightly bright environment. The computer classroom is evaluated as too dark after the lesson by $4 \%$ of panellists. Though the light conditions did not change.

None of the panellists rated noise load as intolerable. From the point of view of noise load, the computer classroom (C) after the lesson is the worst. The mean value of the noise load is 2.40 before the lesson and 2.75 after the lesson. It corresponds with the acceptable noise level. 

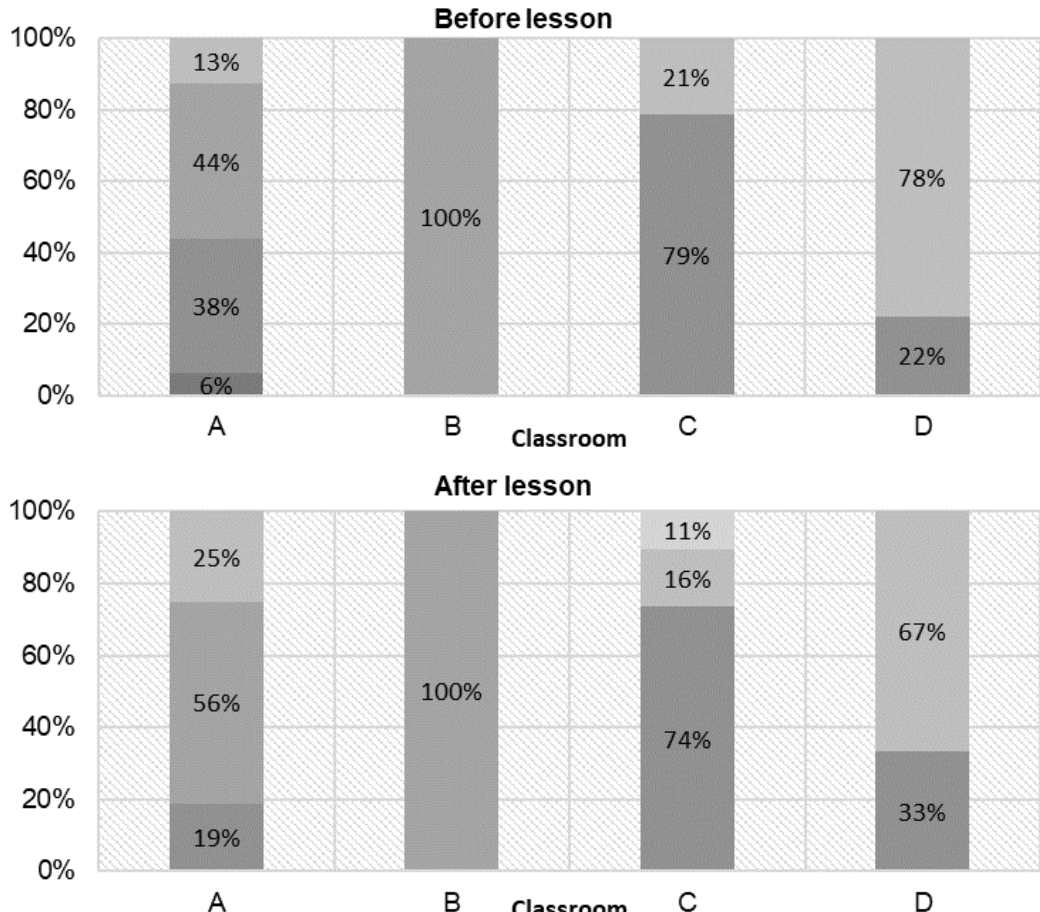

- Too bright $\quad$ Slightly bright $\square$ Just right $\amalg$ Slightly dark $\amalg$ Too dark

Fig. 5. Light comfort in the university classrooms before and after the lesson.

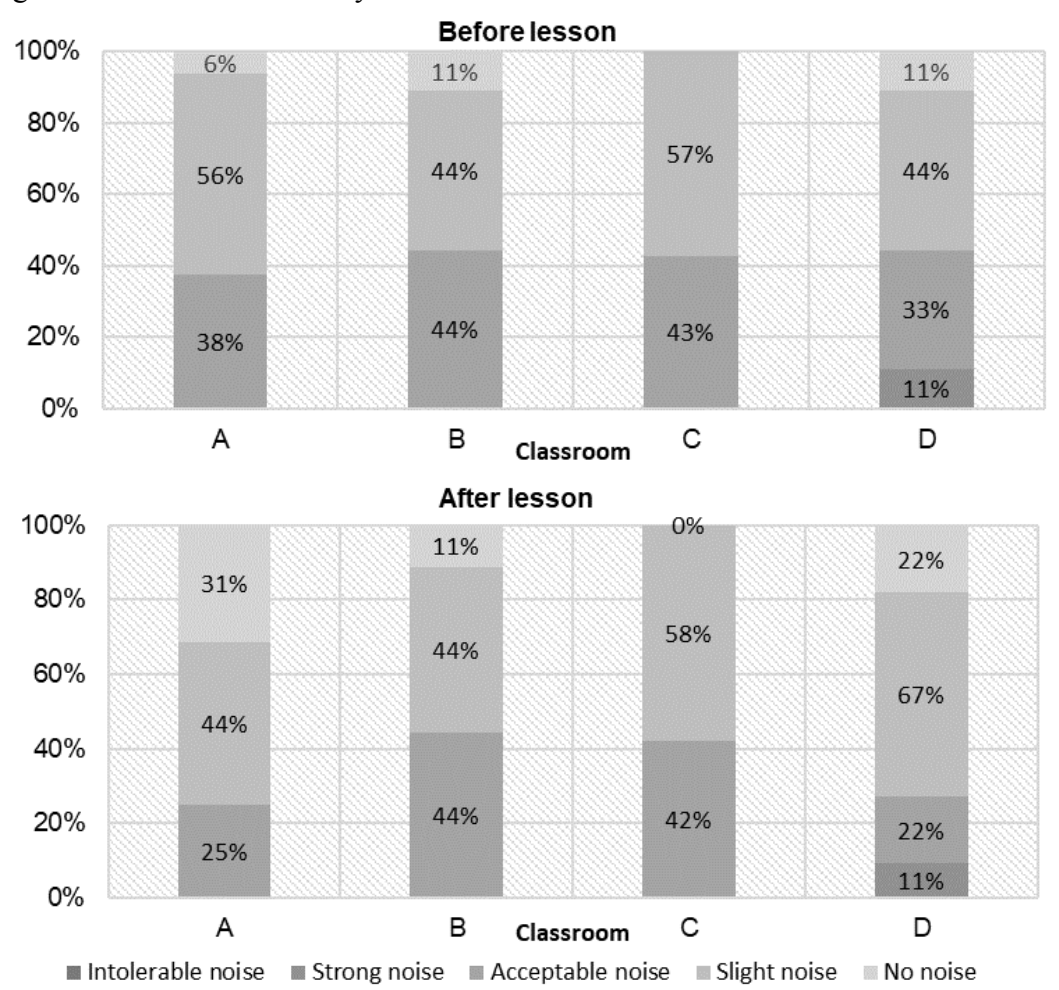

Fig. 6. Noise load in the university classrooms before and after the lesson. 
Table 1. Results of subjective quality assessment in the university classrooms.

\begin{tabular}{|c|c|c|c|c|c|c|}
\hline & \multicolumn{4}{|c|}{ University classrooms } & \multirow{2}{*}{ Summary } \\
\hline & & A & B & $\mathrm{C}$ & $\mathrm{D}$ & \\
\hline \multirow{3}{*}{ Odor intensity } & $\varnothing$ Before lesson & 2.67 & 1.50 & 2.33 & 1.50 & 2.00 \\
\hline & $\varnothing$ After lesson & 2.67 & 1.50 & 3.17 & 1.50 & 2.21 \\
\hline & Trend & $-(0.00)$ & $-(0.00)$ & $\uparrow(0.81)$ & $-(0.00)$ & $\uparrow(0.21)$ \\
\hline \multirow{3}{*}{ Thermal comfort } & $\varnothing$ Before lesson & 2.86 & 1.29 & 2.00 & 1.29 & 1.71 \\
\hline & $\varnothing$ After lesson & 2.86 & 1.29 & 2.71 & 1.29 & 1.89 \\
\hline & Trend & $-(0.00)$ & $-(0.00)$ & $\uparrow(0.71)$ & $-(0.00)$ & $\uparrow(0.18)$ \\
\hline \multirow{3}{*}{ Humidity comfort } & $\varnothing$ Before lesson & 3.20 & 1.80 & 3.20 & 1.80 & 2.50 \\
\hline & $\varnothing$ After lesson & 3.20 & 1.80 & 3.80 & 1.80 & 2.65 \\
\hline & Trend & $-(0.00)$ & $-(0.00)$ & $\uparrow(0.60)$ & $-(0.00)$ & $\uparrow(0.15)$ \\
\hline \multirow{3}{*}{ Light comfort } & $\varnothing$ Before lesson & 3.20 & 1.80 & 2.80 & 1.80 & 2.40 \\
\hline & $\varnothing$ After lesson & 3.20 & 1.80 & 3.80 & 1.80 & 2.65 \\
\hline & Trend & $-(0.00)$ & $-(0.00)$ & $\uparrow(1.00)$ & $-(0.00)$ & $\uparrow(0.25)$ \\
\hline \multirow{3}{*}{ Noise load } & $\varnothing$ Before lesson & 3.20 & 1.80 & 2.80 & 1.80 & 2.40 \\
\hline & $\varnothing$ After lesson & 3.20 & 1.80 & 3.80 & 2.20 & 2.75 \\
\hline & Trend & $-(0.00)$ & $-(0.00)$ & $\uparrow(1.00)$ & $\uparrow(0.40)$ & $\uparrow(0.35)$ \\
\hline
\end{tabular}

\section{Conclusion}

The evaluation of the subjective assessment of the quality of the indoor environment at university classrooms is described within the paper. The indoor parameters such as air acceptable, odor intensity, thermal comfort, humidity comfort, light comfort or noise load are monitored before and after the lesson. Indoor air quality in the rooms which are used for education learning processes has the influence on performance, concentration, and productivity of students. This study contributes with information on university indoor environments in the Czech Republic and their relationship with to the individual components of the internal environment. This knowledge is necessary and useful to develop appropriate strategies to create and maintain the internal environment for education and training.

The contribution is supported by the Specific University Research SVV 201802 Address identification and analysis of the determinants of the Indoor Environment Quality (IEQ).

\section{References}

1. M. Kraus, I. Juhásová Šenitková, IOP Conf. Series: Materials Science and Engineering 245, 042072 (2017)

2. D.A. Krawczyk, B. Wadolowska, Energy Procedia 147, 96-103 (2018)

3. I. Juhásová Šenitková, M. Kraus, SGEM 2018, vol. 18 (6.3), 597-603 (2018)

4. D.L. Johnson, R.A. Lynch, E.L. Floyd, J. Wang, J.N. Bartels, Building and Environment 136, 185-197 (2018)

5. R. Kosonen, F. Tan, Energy and Buildings 36 (10), 981-986 (2004)

6. P. Wargocki, Indoor Air 9 (3), 165-179 (1999)

7. E. Finell, A, Tolvanen, U. Haverinen-Shaughnessy, S. Laaksonen, S. Karvonen, R. Sund, P. Luopa, J. Pekkanen, T. Ståhl, Science of The Total Environment 624, 1504$1512(2018)$ 